Ewout A. Kouwenhoven

Alicia N. Stein-Oakley

Julie A. Maguire

Paula Jablonski

Ron W. F. de Bruin

Napier M. Thomson

\section{Increased expression of basic fibroblast growth factor during chronic rejection in intestinal transplants is associated with macrophage infiltrates}

Received: 12 May 1998

Received after revision: 7 August 1998 Accepted: 23 September 1998

E.A. Kouwenhoven $(-)^{1}$.

A. N. Stein-Oakley

J.A. Maguire - N.M. Thomson

Department of Medicine,

Monash Medical School,

Monash University,

Melbourne, Victoria, Australia

P. Jablonski

Department of Surgery,

Monash Medical Centre,

Monash University,

Melbourne, Victoria, Australia

R.W.F. de Bruin

Department of Surgery,

Erasmus University,

P.O. Box 1738 .

3000 DR Rotterdam, The Netherlands

1 Present address:

Laboratory for Experimental Surgery, Erasmus University, PO Box 1738 ,

3000 DR Rotterdam, The Netherlands Fax: + 31104369140

e-mail: Kouwenhoven@heel.fgg.eur.nl

\begin{abstract}
Long-term survival of intestinal transplants is hampered by chronic rejection (CR). Since transplants with CR demonstrate fibrotic changes, the cytokine basic fibroblast growth factor (bFGF) may be involved in the tissue remodelling of chronic intestinal rejection. The aim of this study was to investigate the bFGF gene and protein expression and distribution in chronically rejecting intestinal allografts. Orthotopic small bowel transplantation was performed in the allogeneic $\mathrm{DA}$ to-AS rat combination. Cyclosporin was administered temporarily to prevent acute rejection. Controls were DA isografts and normal DA. bFGF gene expression was evaluated using reverse transcriptase polymerase chain reaction (RT-PCR) of the ileum RNA and was standardized against Glyceraldehyde-3phosphate-dehydrogenase (GAPDH) expression. bFGF protein was determined using immunohistochemistry. To identify the bFGFpositive cell type, sequential sections were stained for cell markers. Allografts showed histological features
\end{abstract}

of $\mathrm{CR}$, whereas isografts preserved normal architecture. bFGF gene expression was present in normal ileum and significantly upregulated in allografts. Immunohistochemical staining showed a significant increase in bFGF protein compared to isografts. Most bFGF-positive cells were localized in the submucosa and muscularis, particularly around the neural plexus. bFGF-positive cells appeared to be ED-2-positive macrophages, strongly suggesting that the site of bFGF production is the activated macrophage. This study demonstrates increased bFGF mRNA and protein in chronically rejecting intestinal allografts that appear to be produced by macrophages.

Key words Basic fibroblast growth factor, chronic rejection, small bowel transplantation - Small bowel transplantation, macrophage infiltration, chronic rejection . Chronic rejection, small bowel transplantation, basic fibroplast growth factor - Macrophage infiltration, chronic rejection, small bowel transplantation

\section{Introduction}

With improved treatments for acute rejection episodes, intestinal transplantation has evolved over the last decade from a cumbersome procedure with unacceptably high morbidity and mortality to a more acceptable therapy for patients with permanent intestinal failure. Al- though long-term outcome is currently mainly determined by uncontrolled acute rejections and lethal infections, it is also hampered by chronic rejection $[1,19]$, which is the leading cause of late graft loss of other organs, such as the heart and kidney $[4,13]$. Indeed, some patients have lost their small bowel transplant due to chronic rejection $[9,23]$. 
In contrast to our knowledge of the nature of the immune response and production of cytokines during acute intestinal rejection [31], little is known about the involvement of cytokines in the pathophysiology of chronic rejection of intestinal transplants. The Pittsburgh group has given some attention to this issue. They demonstrated an increased expression of the cytokines IL- 4 and interferon- $\gamma$ in chronically rejecting intestinal allografts, mainly localized in the thickened muscularis externa $[30,33]$. To further understand the mechanisms of tissue remodelling during chronic rejection of the small bowel, we have recently developed a rat model [3]. Histomorphological analysis has demonstrated mesenteric inflammation with sclerosis, myointimal proliferation of mesenteric vessels, thickening of the muscularis, crypt hyperplasia, blunting of villi, and loss of goblet cells, features that have been found both in humans and in other animal models $[6,16,19]$. Some of these characteristics are consistent with the possible involvement of fibrogenic growth factors such as basic fibroblast growth factor (bFGF) and have been observed in other organs $[12,18]$.

bFGF, or fibroblast growth factor-2 (FGF-2), a member of the FGF family, is a 133 to 154 amino acid (17.5 kDa) peptide that is mitogenic for vascular endothelial cells, smooth muscle cells, fibroblasts, and neural cells and chemotactic for macrophages and endothelial cells. It has been involved in wound healing and tissue regeneration [8]. bFGF has a high affinity for heparin and heparan sulphate proteoglycans, and it can thus be found in the extracellular matrix or bound to basement membranes [7]. The binding of bFGF to heparan sulphate proteoglycans protects it from inactivation by endogenous proteolytic agents.

In the digestive tract, bFGF peptide has been detected in duodenum [15] and in normal gastric and colonic mucosa. It has been immunohistochemically localized to vessels, fibroblasts, and macrophages, with epithelial cells and extracellular matrix demonstrating no bFGF immunoreactivity [21]. Heparan sulphate proteoglycans act as the low-affinity receptors for bFGF in the intestine [17], forming an FGF-heparin complex that facilitates the interaction between FGFs and their high-affinity cell surface tyrosine kinase receptors. The latter have been identified on various cell types, including smooth muscle cells, endothelial cells, macrophages, and intestinal epithelial cells $[11,14]$.

The function of bFGF in the small intestine is not well defined. bFGF failed to promote epithelial restitution after colonic mucosal damage in vitro [24]. Production of bFGF in the adult ileum has not yet been described. However, bFGF is known to be produced by activated macrophages, smooth muscle cells, and fibroblasts $[8,11]$, and just these sources of bFGF could be important in the tissue remodelling processes of chronic intestinal rejection.
The aim of the present study was to evaluate the possible involvement of bFGF in the pathophysiology of chronic intestinal allograft rejection by analyzing gene and protein expression and distribution in the course of chronic rejection.

\section{Materials and methods}

\section{Groups}

All experimental procedures involving animals conformed to the National Health and Medical Research Council Code of Practice and were approved by Monash Medical Centre Animal Ethics Committee B and the Monash Standing Committee on Ethics in Animal Experimentation.

\section{Chronic rejection model}

The model of chronic rejection after small bowel transplantation has been described previously [3]. In brief, male, aduit inbred Dark-Agouti (DA)(RT-1 ${ }^{\text {avl }}$ ) and Albino-Surgery (AS)(RT-1') rats, obtained from Monash Animal Services, were used. Onestep orthotopic total small bowel transplantation was performed, as deseribed previously [26], in the allogeneic DA-to-AS rat combination. Cyclosporin, $5 \mathrm{mg} / \mathrm{kg}$ per day was administered from day -2 until day 9 to prevent acute rejection. Rats were sacrificed at 50 days $(n=6)$ or 100 days $(n=5)$ post-transplantation. Small bowel grafts were removed and processed for histopathology, immunohistochemistry, and reverse transcriptase polymerase chain reaction ( $\mathrm{RT}$-PCR).

\section{Isografts}

Untreated DA isografts were included to control for nonallogeneic injury. Rats were sacrificed and grafts were removed at 50 days $(n=6)$ or 100 days $(n=5)$ post-transplantation.

\section{Normal rat small bowel $(D A)$}

Four small bowels from age-matched, normal DA rats were used as controls.

\section{Processing of grafts}

Small bowel grafts were retrieved under ether anesthesia, and rats were sacrificed immediately thereafter. Portions of the ileum measuring approximately $1 \mathrm{~cm}$ were fixed in $10 \%$ buffered formalin and embedded in paraffin for histopathological studies and either snap-frozen in Tissue-Tek ${ }^{(0 . C . T . ~ c o m p o u n d) ~(O C T) ~ f o r ~ i m m u-~}$ nohistochemistry or placed directly in liquid nitrogen for RNA extraction.

\section{Histopathology}

Paraffin sections, stained with hematoxylin and eosin, were assessed in a blinded manner by two observers. The incidence of the following features was recorded for each of nine high-power fields $(400 \times)$ : (a) blunting of villi and goblet cell loss; (b) crypt hyper- 
plasia and necrosis; (c) thickening of the muscularis; and (d) inflammatory cell infiltration, vascular damage, and sclerosis of the mesentery. Scores of $0,1,2$, or 3 were assigned to features not observed or observed in $1 / 3,2 / 3$, or all fields, respectively. Results obtained for each feature were added up, and added scores of 0 were classified as no damage, 1-3 as very mild (grade 1), 4-6 mild (grade 2), 7-9 moderate (grade 3), and 10-12 severe (grade 4).

\section{Immunohistochemistry}

Immunoreactive bFGF was assessed on 4- $\mu \mathrm{m}$ cryostat sections postfixed in periodate lysine paraformaldehyde (PLP) by a four-layer immunoperoxidase technique. Briefly, nonspecific binding was blocked by preincubation with $10 \%$ normal rabbit serum (Dako, Christchurch, New Zealand) in phosphate-buffered saline (PBS) with $0.01 \%$ sodium azide at room temperature. This was followed by overnight incubation with the primary mouse anti-bFGF (Upstate Biotechnology) and cell surface marker ED-2 (a gift from Dr. C.D. Dijkstra, Amsterdam, The Netherlands). After each incubation, slides were washed in PBS-0.2\% gelatin. A second layer, goat anti-mouse IgG (Sigma, Castle Hill, Australia), was then applied for $30 \mathrm{~min}$. Endogenous peroxidase activity was blocked by incubation for $10 \mathrm{~min}$ in methanol $/ 0.3 \% \mathrm{H}_{2} \mathrm{O}_{2}$, after dehydration through graded alcohol. After rehydration and washing, the third and fourth layers - rabbit-anti goat immunoglobulin (Dako) and goat peroxidase anti-peroxidase (Dako) - were each applied for $30 \mathrm{~min}$. The reaction was developed by the addition of metal-enhanced diaminobenzidine substrate (Pierce), and slides were counterstained in Harris hematoxylin, dehydrated, cleared, and mounted.

Negative controls included sections in which the primary antibody was omitted for every animal. Isotype-specific control monoclonal antibodies (Dako) were also used. No staining was observed with these irrelevant antibodies.

The specificity of the antibodies to bFGF was confirmed by a solid phase absorption study, as previously described [29].

The immunohistochemical staining was analyzed by two observers, blind with regard to treatment group and time post-transplantation. Positive cells were counted in four different compartments of the ileum - villi, crypts, submucosa, and muscularis and were expressed as numbers of positive cells per $0.1 \mathrm{~mm}^{2}$.

Semiquantative reverse transcriptase polymerase chain reaction

\section{RNA preparation}

Total RNA was extracted from approximately $100 \mathrm{mg}$ of snap-frozen, full-thickness ileum using the RNAzol ${ }^{\mathrm{m}} \mathrm{B}$ method (Tel-test, Friendswood, Calif., USA). RNA was quantified spectrophotometrically and samples were diluted to $2.5 \mu \mathrm{g} / \mu \mathrm{l}$.

\section{cDNA synthesis}

Reverse transcription reactions were set up using $1 \mu$ l of RNA $(2.5 \mu \mathrm{g})$ in $20-\mu \mathrm{l}$ volumes using an MULV R'T system (Perkin Elmer, Foster City, Calif., USA).

\section{PCR DNA amplification}

PCR reactions were performed using a PCR amplification kit with AmpliTaq gold (Perkin Elmer). The co-amplification reaction for bFGF and glyceraldehyde-3-phosphate-dehydrogenase (GAP-
DH) genes was optimized to ensure that the amplification of both genes was within the exponential phase at the end point of the PCR. Different concentrations of the primer pairs and of the Amplitaq gold were tested. Based on optimization experiments, PCR amplification reactions were performed in $25-\mu$ l volumes and contained $1.5 \mathrm{mM} \mathrm{MgCl} 2, \times 1$ PCR buffer, $1.25 \mathrm{U}$ AmpliTaq gold, $100 \mathrm{nM}$ bFGF, $100 \mathrm{nM}$ GAPDH, and $2.5 \mu \mathrm{lDNA}$. The following primers were used: bFGF sense: fluorescein (Fl)TCACTTCGCTTCCCGCACTG (549), antisense CCAGCAGCCGTCCATCTT (787); GAPDH sense: Fl-CCTTCATTGACCTCAACTACATG (131), antisense: GATGACCTTGCCCACAGCCTT (667). The position of the 5 nucleotide of each primer in the published sequences $[28,32]$ is included within parentheses. Following an activating step for $12 \mathrm{~min}$ at $94^{\circ} \mathrm{C}, 35$ cycles were performed with a denaturation step of $1 \mathrm{~min}$ at $94^{\circ} \mathrm{C}$, an annealing temperature for $1 \mathrm{~min}$ and $30 \mathrm{sec}$ starting at $72^{\circ} \mathrm{C}$ and decreasing by $0.4^{\circ} \mathrm{C}$ per cycle until $64^{\circ} \mathrm{C}$, and an extension step of $2 \mathrm{~min}$ at $72^{\circ} \mathrm{C}$. The resulting PCR products had a length of 238 and $536 \mathrm{bp}$ for $b F G F$ and GAPDH respectively. The GAPDH primers were designed by Dr. P. Aldred and kindly provided by Dr. N. Cranswick. No interference was demonstrated between primer pairs.

\section{Analysis of PCR products}

The sense primers were labelled with fluorescein at the 5' end for direct detection of the PCR product bands using a laser-based fluorescence DNA detection system (Fluorimager 575-Molecular Dynamics, Sunnyvale, Calif., USA). The volume of the individual bands was integrated using ImageQuant software (Molecular Dynamics), and ratios between $\mathrm{bFGF}$ and GAPDH bands were calculated. Four normal DA ileum samples were amplified and run with each group containing all isografts or allografts at day 50 or day 100 to enable comparisons between each group of amplified samples. Results obtained with normal DA were standardized to 1 . All sam. ples were amplified and run in duplicate.

\section{Statistical analysis}

All statistical analyses were performed using SPSS for Windows. A Kruskal-Wallis nonparametric ANOVA was done, followed by Mann-Whitney $U$-test and Spearman correlations. The results are expressed as mean \pm SEM. A $P$ value below 0.05 was accepted as significant.

\section{Results}

Histology

All allogeneic transplants developed chronic rejection (CR), although the severity of damage varied among animals from very mild to moderate. At 50 days, four out of six animals had moderate CR (grade 3 ). A progression of chronic damage with time was not evident. At 100 days post-transplantation, two of five rats had moderate changes. All other grafts had mild changes. Syngeneic grafts retained a normal architecture. 


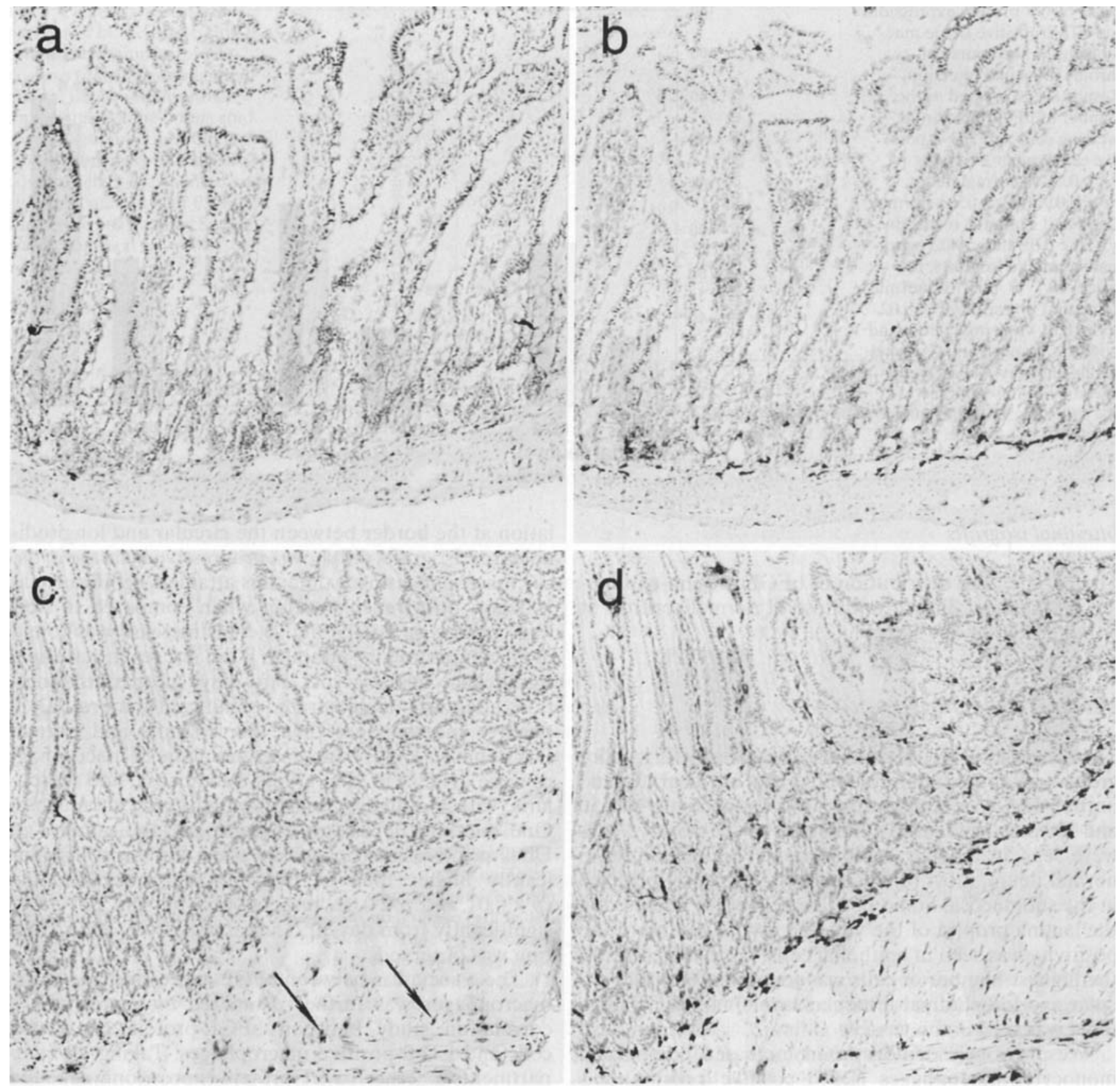

Fig. 1a bFGF protein expression in a normal small intestine b Normal distribution of tissue macrophages in the small intestine of a DA rat. c, d Chronically rejecting intestinal allografts demonstrating an increased number of bFGF-positive cells and tissue macrophages. The highest increase was found in the submucosa and in the muscularis, particularly between the circular and longitudinal layers (arrow)

\section{Immunohistology}

Normal ileum (Figs. 1a,2)

The highest density of bFGF protein-expressing cells was located in the submucosa; a few positive cells were detected in the lamina propria of the villi and crypts, whereas epithelial cells were negative. bFGF-positive cells were present throughout the muscularis, their density being highest between the circular and longitudinal layers. Vessels did not show bFGF reactivity. 
Fig. 2 bFGF protein expression and ED-2-positive tissue macrophages in the course of chronic intestinal rejection. Results are expressed as the number of bFGF protein-expressing cells and ED-2-positive cells (mean \pm SEM).

${ }^{* 1} P<0.05$ vs normal ileum;

${ }^{* 2} \mathrm{P}<0.01$ and $<0.05$ vs normal ileum and isografts, respectively; ${ }^{* 3} P<0.05$ and $<0.02$ vs normal ileum and isografts, respectively; ${ }^{*} P<0.01$ vs normal ileum and isografts; ${ }^{* 5} P<0.02$ and $<0.01$ vs normal ileum and isografts, respectively (Kruskal Wallis one-way ANOVA, followed by Mann-Whitney Utest). $\square$ Day $50 ; \square$ day 100

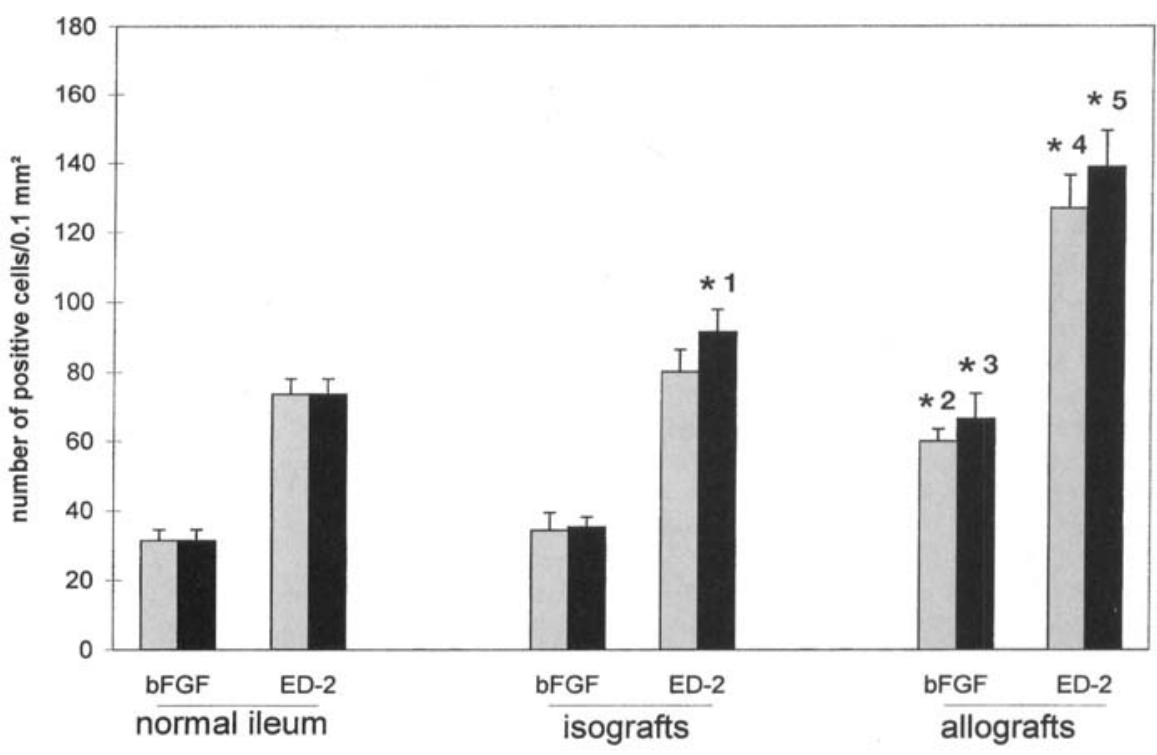

\section{Intestinal isografts}

The number and distribution of bFGF protein-expressing cells did not differ from those of normal controls at either day 50 or day 100 (Fig.2).

\section{Intestinal allografts (Figs. 1c,2)}

The number of bFGF protein-expressing cells in allografts was approximately double that of isografts and normal DA ( $p<0.05$ and $p<0.01$, respectively) at 50 and 100 days. Increased numbers of bFGF-positive cells were seen in all four compartments evaluated. As in normal ileum, most bFGF-positive cells were localized in the submucosa. Some positive cells were detected in the lamina propria of the villi and crypts, but no bFGF positivity was seen in epithelial cells. As in the controls, the highest number of cells was found between the circular and longitudinal muscular layers. No bFGF positivity was seen in the vessels.

We previously demonstrated increased numbers of monocytes/macrophages (ED-1-positive cells) and $T$ cells during chronic rejection of small bowel allografts [3]. Staining of sequential sections was performed to identify the lineage of the bFGF-positive cells in our model. As shown in Figs. $1 \mathrm{~b}$ and $1 \mathrm{~d}$, many cells expressing bFGF protein appeared in sequential sections to be ED-2-positive tissue macrophages.

Immunohistochemical staining of normal DA ileum with ED-2 antibody demonstrated that the highest number of ED-2-positive cells was present in the submucosa. Very few tissue macrophages were present in the villi. The density was somewhat higher in the crypts. There were some positive cells in the muscularis, with accumu- lation at the border between the circular and longitudinal layer. Isografts did show a progressive increase in tissue macrophages over time; this attained significance at 100 days post-transplantation when compared to normal controls $(p<0.05 ;$ Fig. 2$)$. This increase was found in all compartments, although it did not reach statistical significance in the crypts. Fifty days after transplantation, allografts demonstrated significantly more ED-2positive macrophages than did isografts and normal DA ileum $(p<0.01)$. Increased numbers of macrophages were evident in villi, crypts, submucosa, and muscularis, with the highest density found in the submucosa. One hundred days after engraftment, the number of ED-2-positive macrophages in allografts was still significantly higher than in isografts and normal ileum ( $p<0.01$ and $p<0.02$, respectively) but did not differ significantly from day 50 . The same pattern of distribution was observed.

The association between bFGF expression and tissue macrophages was further examined by performing a correlation study between bFGF-protein expressing cells and ED-2-positive macrophages. Taking all compartments together, bFGF protein expression was found to be significantly correlated with the number of tissue macrophages ( $R=0.86, p<0.001, n=25$; Fig. 3 ).

Furthermore, the number of bFGF protein-expressing cells was significantly correlated with the severity of chronic rejection $(R=0.80, p<0.001, n=21$; Fig. 4$)$.

\section{RT-PCR}

The bFGF gene was transcriptionally active in normal DA ileum (Fig. 5). Allografts demonstrated a significant increase in bFGF mRNA levels at 50 and 100 days post- 
Fig. 3 Correlation between the number of bFGF-expressing cells and the number of ED-2positive tissue macrophages in normal ileum and intestinal transplants at time points studied. The number of bFGF protein-expressing cells and ED-2positive cells were counted and given as a quantity per $0.1 \mathrm{~mm}^{2}$. Data were analyzed by Spearman correlation $(R=0.86$, $p<0.001, n=25)$
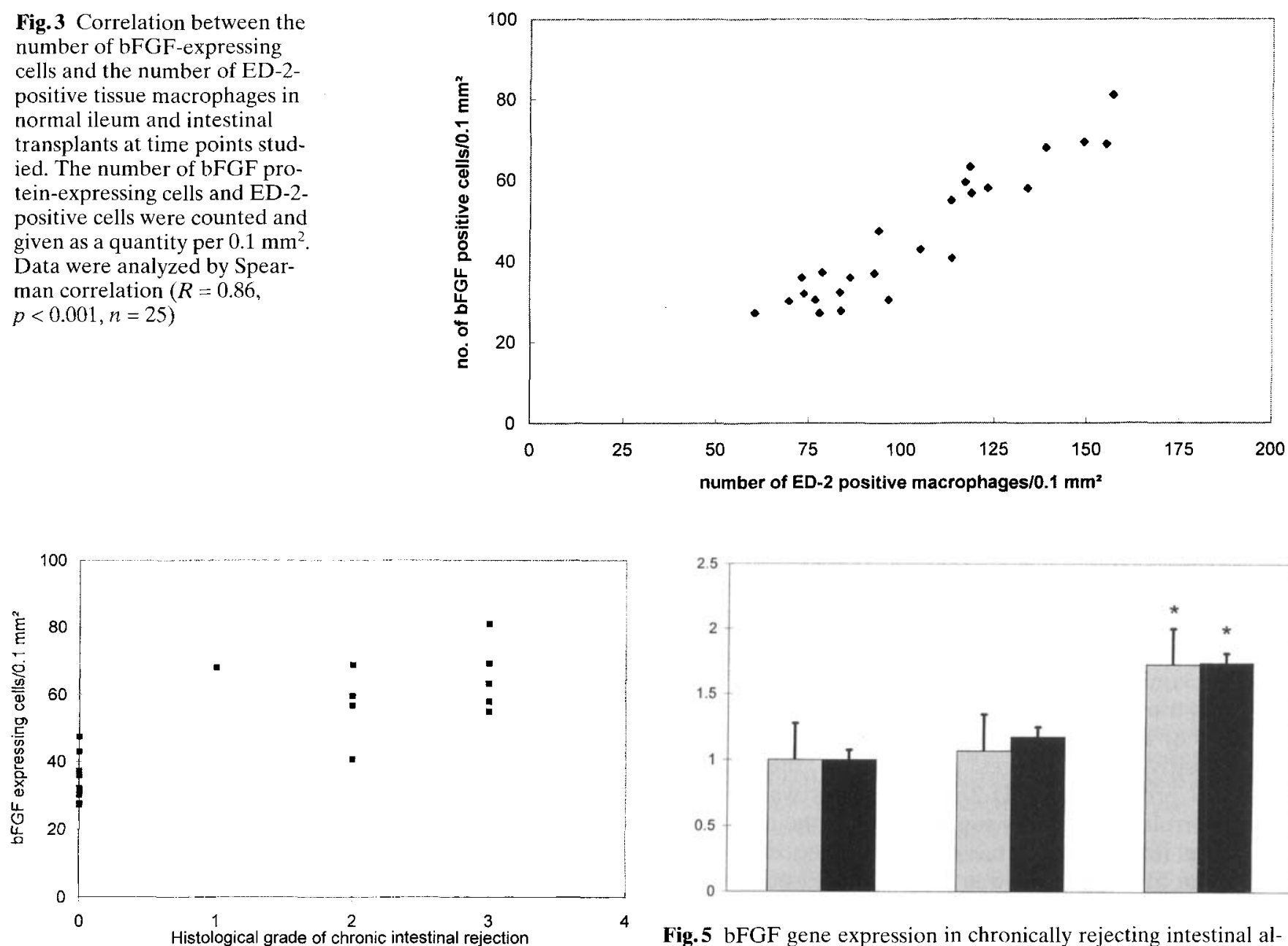

Fig. 4 bFGF protein and the histological grade of chronic intestinal rejection. The severity of chronic changes, including blunting of villi and goblet cell loss, crypt hyperplasia and necrosis, thickening of the muscularis, inflammatory cell infiltrate vascular damage, and sclerosis of the mesentery, were classified as no damage (grade 0), very mild (grade 1), mild (grade 2 ), moderate (grade 3 ), or severe damage (grade 4). The number of bFGF protein-expressing cells were counted and given as a quantity per $0.1 \mathrm{~mm}^{2}$. Data were analyzed by Spearman correlation $(R=0.80, p<0.001, n=21)$

transplantation compared to normal controls $(p<0.01$ and $p<0.02$, respectively). The $b F G F m R N A$ of isografts was not postoperatively modified compared to normal DA controls. bFGF gene expression was correlated with the histological grade of chronic rejection $(R=0.55, p<0.02, n=21)$.

\section{Discussion}

Long-term survival of intestinal transplants is hampered by chronic rejection, the major cause of graft loss of other transplanted organs, such as the kidney and heart $[4$,

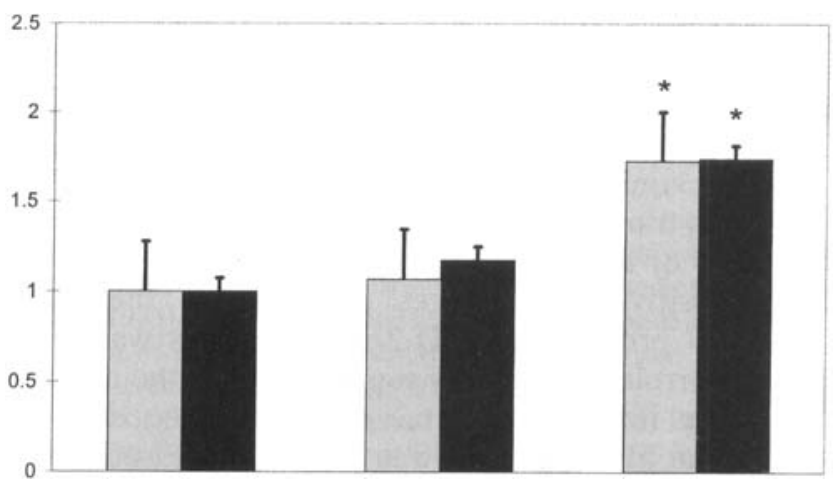

Fig.5 bFGF gene expression in chronically rejecting intestinal allografts. Results are expressed as bFGF/GAPDH ratio, standardized to normal DA ileum, with mean \pm SEM. Units are arbitrary. ${ }^{*} p<0.02$ vs normal DA ileum (Kruskal-Wallis one-way ANOVA, followed by Mann-Whitney U-test). Day 50; day 100

13]. Chronic rejection of transplanted organs is characterized by an inflammatory infiltrate, graft arteriosclerosis, and fibrosis. Small bowel-specific features include thickening of the muscularis externa, crypt hyperplasia, and blunting of villi $[3,16,19]$.

Because of its effects on smooth muscle cells, fibroblasts, and the extracellular matrix, bFGF would appear to be involved in the tissue remodelling of chronic rejection in intestinal transplants, as demonstrated in other organs $[12,18]$. Moreover, bFGF has been found to act as a chemoattractant for macrophages [20], a cell type that has repeatedly been observed in chronically rejected organs.

The present study showed the bFGF gene to be transcriptionally active in the ileum. This is the first time that bFGF mRNA has been detected in the adult intestine. Chowdhury et al. could not detect any signal in 
normal colorectal mucosa using RT-PCR [5]. Shimasaki et al. found that bFGF measured by Northern blot analysis could not be detected in the small intestine [28]. Our use of the full thickness of the intestine, combined with a sensitive RT-PCR protocol, may explain these differences. The bFGF protein was also present in normal and rejecting ileum.

The main finding of this study was a significant increase in bFGF mRNA and protein in chronic intestinal allograft rejection. This enhanced bFGF expression appeared to be correlated with the histological damage of the intestinal grafts, further suggesting a role for this growth factor in the tissue remodelling. In contrast, chronic vascular rejection in lung allografts did not coincide with bFGF immunoreactivity; bFGF was only markedly upregulated in the early phase and restricted to peribronchiolar and perivascular infiltrates [18]. Nor did bFGF correlate with the degree of transplant vasculopathy in bioptied heart allografts $[27,34]$ or in aorta allografts [22]. Indeed, myoproliferation of the intra-intestinal arteries was not accompanied by enhanced bFGF immunoreactivity. Therefore, bFGF appears to be important in organ-specific remodelling, i. e., in muscular thickening and neuron repair, rather than being involved in transplant arteriosclerosis.

Many of the bFGF-expressing cells appeared to be ED-2-positive macrophages. Furthermore, the number of bFGF protein and ED-2-positive cells was significantly correlated, strongly suggesting that the macrophage is an important source of bFGF. Lee et al. also found that bFGF protein was mainly expressed by infiltrating cells, including macrophages, in lung allografts [18]. The production of bFGF by macrophages has been unequivocally demonstrated by PCR and Northern blot analysis of macrophage mRNA [11].

bFGF-expressing cells and tissue macrophages in allografts were mainly localized in the submucosa and the muscularis, particularly between the longitudinal and circular layers. Since the neural plexus are localized in these areas, bFGF and macrophages may not only be associated with muscular thickening, but may also act in the intrinsic neural plexus. Lee et al. found a suppressed neuromuscular transmission during subclinical chronic intestinal rejection that is related to the loss of enteric neurons as a consequence of extrinsic denervation [10]. Since bFGF is known to stimulate neuron outgrowth [8], the preferential site of bFGF-expressing cells could reflect an attempt to repair the intrinsic neural plexus.

We did not detect bFGF protein immunohistochemically in epithelial cells of normal intestine, which is consistent with the results of Ohtani et al. [21]. Moreover, no staining was seen in the damaged mucosa of chronically rejecting intestinal allografts, suggesting that endogenous bFGF is not involved in the repair of epithelial damage in CR.

Although the influx of macrophages into isografts was significantly higher than in normal ileum, histologically the intestinal grafts were well preserved during follow-up. Also, bFGF protein and mRNA remained at the nontransplanted level, further suggesting that the macrophages in the isografts were inactive.

Based on the present data, we postulate that bFGF may have important effects that contribute to CR of intestinal grafts. bFGF is a chemoattractant for macrophages, contributing to the persistent increase in macrophages in chronic intestinal rejection. Activated macrophages, in turn, produce bFGF and other fibrogenic cytokines, including TGF-beta and PDGF, and have been shown to play a pivotal role in the process of CR $[2$, 25]. bFGF also has a mitogenic effect on smooth muscle cells, enhancing the hypertrophy of the muscularis. The localization of bFGF also suggests that it may have a positive effect on neuron outgrowth.

To further understand the contribution of bFGF to $\mathrm{CR}$ and its relationship with tissue macrophages, studies on the effect of neutralization of bFGF protein and on the effect of a selective inhibition of macrophages should be performed.

Acknowledgements E.A. Kouwenhoven was supported by a grant from the Dutch College of Surgeons.

\section{References}

1. Abu-Elmagd K, Reyes J, Todo S, Rao A, Lee R, Irish W, Furukawa $H$, Bueno J, McMichael J, Fawzy AT, Murase N, Demetris J, Rakela J, Fung JJ, Starzl TE (1998) Clinical intestinal transplantation: new perspectives and immunologic considerations. J Am Coll Surg 186: $512-527$
2. Azuma $H$, Nadeau $K C$, Ishibashi $M$, Tilney NL (1995) Prevention of functional, structural, and molecular changes of chronic rejection of rat renal allografts by a specific macrophage inhibitor. Transplantation 60: 1577-1582

3. Bruin R de, Stein-Oakley A, Jablonski P, Dowling J, Thomson N (1995) Chronic rejection after small-bowel transplantation. Transplant Proc 27: 3580
4. Cecka JM (1994) Outcome statistics of renal transplants with an emphasis on long-term survival. Clin Transplant 8: 324-327

5. Chowdhury A, Fukuda R, Fukumoto $S$ (1996) Growth factor mRNA expression in normal colorectal mucosa and in uninvolved mucosa from ulcerative colitis patients. J Gastroenterol Hepatol 31: $353-360$ 
6. Diliz-Perez HS, McClure J, Bedetti C, Hong HQ, Santibanes E de, Shaw BW Jr, Van Thiel D, Iwatsuki S, Starzl TE (1984) Successful small bowel allotransplantation in dogs with cyclosporine and prednisone. Transplantation 37: $126-129$

7. Folkman J, Klagsburn M, Sasse J, Wadzinski M, Ingber D, Vlodavsky I (1988) A heparin binding angiogenic protein basic fibroblast growth factor - is stored within the basement membrane. Am J Pathol 130: 393-400

8. Gospodarowicz D (1991) Fibroblast growth factors. In: Aggerwal BB, Gutterman JU (eds) Human cytokines. Handbook for basic and clinical research. Blackwell Scientific Publications, Boston, pp 329-341

9. Goulet O, Jan D, Sarnacki S, Brousse $\mathrm{N}$, Colomb V, Salomon R, Cuenod B, Piloquet $\mathrm{H}$, Ricour C, Revillon $\mathrm{Y}$ (1996) Isolated and combined liversmall bowel transplantation in Paris: 1987-1995. Transplant Proc 28: 2750

10. Heeckt PF, Lee KKW, Halfter WM, Schraut WH, Bauer AJ (1995) Functional impairment of enteric smooth muscle and nerves caused by chronic intestinal allograft rejection regresses after FK 506 rescue. Transplantation 59: 159-164

11. Henke C, Marinieli W, Jessurun J, Fox J, Harms D, Peterson M, Chiang L, Doran P (1993) Macrophage production of basic fibroblast growth factor in the fibroproliferative disorder of alveolar fibrosis after lung injury. Am J Pathol 143: 1189-1199

12. Hirabayashi T, Demertzis S, Schafers $\mathbf{J}$, Hoshino K, Nashan B (1996) Chronic rejection in lung allografts: immunohistological analysis of fibrogenesis. Transpl Int 9: S293-295

13. Hosenpud JD, Novick RJ, Bennett LE Keck BM, Fiol B, Daily OP (1996) The Registry of the International Society for Heart and Lung Transplantation: Thirteenth official report-1996. J Heart Lung Transplant 15: 655-674

14. Kanai M, Rosenberg I, Podolsky DK (1997) Cytokine regulation of fibroblast growth factor receptor 3 IIIb in intestinal epithelial cells. Am J Physiol 272: G885-893

15. Kusstatscher S, Bishop J, Brown L, Sandor S, Szabo S (1993) Basic fibroblast growth factor (bFGF) immunolocalization in duodenum of normal rats and after duodenal ulcer induction. Gastroenterology 104: A125

16. Langrehr JM, Banner B, Lee KKW, Schraut WH (1993) Clinical course, morphology and treatment of chronically rejecting small bowel allografts. Transplantation 55: 242 -250
17. Ledoux D, Mereau A, Daucel MC Barritault D, Courty J (1989) Distribution of basic fibroblast growth factor binding sites in various tissue membrane preparations from adult guinea pig. Biochem Biophys Res Commun 159: 290-296

18. Lee AGL, Wagner FM, Giaid A, Chen MF, Hamid Q, Serrick C, Shennib H (1997) Immunohistochemical characterization of inflammatory and proliferative events during chronic rejection in rat lung allografts. Transplantation 64: 465-471

19. Lee RG, Nakamura K, Tsamandas AC, Abu-Elmagd K, Furukawa $\mathrm{H}$, Hutson WR, Reyes J, Tabasco-Minguillan JS, Todo S, Demetris AJ (1996) Pathology of human intestinal transplantation. Gastroenterology 110: 1820-1834

20. Lefaucheur JP, Gjata B, Lafont H, Sebille A (1996) Angiogenic and inflammatory responses following skeletal muscle injury are altered by immune neutralization of endogenous basic fibroblast growth factor, insulin-like growth factor- 1 and transforming growth factor -beta 1. J Neuroimmunol 70: $37-44$

21. Ohtani H, Nakamura S, Watanabe Y, Mizoi T, Saku T, Nagura H (1993) Immunocytochemical localization of basic fibroblast growth factor in carcinomas and inflammatory lesions of the human digestive tract. Lab Invest 68 : 520-527

22. Räisänen-Sokolowski A, Vuoristo P, Myllärniemi M, Yilmaz S, Kallio E, Hăyry P (1995) Mycophenolate mofetil (MMF, RS-61 443) inhibits inflammation and smooth muscle proliferation in rat aortic allografts. Transpl Immunol 3: $341-350$

23. Reyes J, Bueno J, Kocoshis S, Green M, Abu-Elmagd K, Furukawa H, Barksdale EM, Strom S, Fung JJ, Todo S, Irish W, Starzl TE (1998) Current status of intestinal transplantation in children. J Pediatr Surg 33: 243-254

24. Riegler M, Sedivy R, Sogukoglu T, Cosentini E, Bischof G, Teleky B, Feil W, Schiessel R, Hamilton G, Wenzl E (1997) Effect of growth factors on epithelial restitution of human colonic mucosa in vitro. Scand J Gastroenterol 32: 925-932

25. Russell ME, Wallace AF, Hancock WW, Sayegh MM, Adams DH, Sibuga NE, Wyner LR, Karnovsky MJ (1995) Upregulation of cytokines associated with macrophage activation in the Lewis-to-F344 rat transplantation model of chronic cardiac rejection. Transplantation 59: 572-578
26. Saat RE, Heineman E. Bruin RWF de, Marquet RL, Jeekel J (1989) Total orthotopic allogeneic small bowel transplantation in rats: attempts to ameliorate the graft-versus-host disease by irradiation and transfusions to the donor Transplantation 221: 236-240

27. Shaddy RE, Hammond EH, Yowell RL (1996) Immunohistochemical analysis of platelet-derived growth factor and basic fibroblast growth factor in cardiac biopsy and autopsy specimens of heart transplant patients. Am J Cardiol 77: 1210-1215

28. Shimasaki S, Emoto N. Koba A, Mercado M, Shibata F, Cooksey K, Baird A, Ling N (1988) Complementary DNA cloning and sequencing of rat ovarian basic fibroblast growth factor and tissue distribution study of its mRNA. Biochem Biophys Res Commun 157: 256-263

29. Stein-Oakley AN, Maguire JA, Dowling J, Perry G, Thomson NM (1997) Altered expression of fibrogenic growth factors in IgA nephropathy and focal and segmental glomerulosclerosis. Kidney Int 51: 195-204

30. Su GL, Walgenbach K-J, Heeckt PH, Wang $\mathrm{Q}$, Halfter $\mathrm{W}$, Whiteside TL, Bauer AJ (1996) Increased expression of interferon- $\gamma$ in a rat model of chronic intestinal allograft rejection. Transplantation 62: 242-248

31. Toogood GJ, Rankin AM, Tam PKH, Morris PJ, Dallman MJ (1996) The immune response following small bowel transplantation - an unusual pattern of cytokine expression. Transplantation 62: $851-855$

32. Tso JY, Sun XH, Kao TH, Reece KS, Wu R (1985) Isolation and characterization of rat and human glyceraldehyde-3-phosphate dehydrogenase cDNAs: genomic complexity and molecular evolution of the gene. Nucleic Acids Res 13:2485-2502

33. Walgenbach K-J, Heeckt PF, Stanson JD, Whiteside TL, Bauer AJ (1996) Increased presence of mast cells and interleukin-4 during chronic rejection of rat intestinal allografts. Transplant Proc 28: 2454

34. Zhao XM, Yeoh TK, Frist WH, Porterfield DL, Miller GG (1994) Induction of acidic fibroblast growth factor and fulllength platelet-derived growth factor expression in human cardiac allografts. Circulation 90: 677-685 